\title{
UMA HISTÓRIA POLÍTICA DA SUBJETIVIDADE eM Michel Foucault
}

\author{
Rodrigo Diaz de Vivar Y Soler
}

\begin{abstract}
Resumo
O tema investigado corresponde à questão da subjetividade em Foucault a partir de uma leitura crítica percorrendo os seus textos na transversal em três deslocamentos de análise. Na arqueologia constata-se a existência do sujeito do enunciado enquanto figura derivada dos jogos de objetivação. Na genealogia surge a noção de individuo situado nas relações de poder. Na genealogia da ética emerge o sujeito produzido pelas experiências éticas. Conclui-se que contra o universalismo das teorias do sujeito, essas formas de subjetividade apontam para uma "ontologia histórica de nós mesmos" oportunizando não descobrirmos o que somos, e sim recusarmos o que nos tornamos.
\end{abstract}

Palavras-chave: Michel Foucault; subjetividade; politica; história.

\section{A POlitical history OF THE SUBJECTIVITY in Michel Foucault}

\begin{abstract}
This investigated corresponds to the question of the subjectivity in Foucault from a critical reading. In archaeology it is evidenced existence of the subject of the enunciation while it appears derived from the objectivization games. In the genealogy, the notion appears of situated individual in the relations of power. In the genealogy of the ethics, the subject produced for the ethical experiences. Concludes that against the universalism of the subject's theories, these forms of subjectivity point with respect to a "historical ontologies of ourselves" letting not to discover what we are, and yes to refuse what in we become them.
\end{abstract}

Keywords: Michel Foucault; subjectivity; political; history.

\footnotetext{
^ Bacharel em Psicologia pela Universidade do Extremo Sul Catarinense - UNESC. Aluno Regular do Programa de Pós - Graduação em Psicologia da Universidade Federal de Santa Catarina UFSC. Endereço: Universidade Federal de Santa Catarina, Bairro Trindade. CEP: 88040-970 - Florianópolis, SC - Brasil.

E-mail:diazsoler@gmail.com
} 
A explosão não vai acontecer hoje. Ainda é muito cedo. Ou tarde demais. Não venho armado de verdades decisivas. Minha consciência não é dotada de fulgurâncias essenciais. Entretanto, com toda a serenidade, penso que é bom que certas coisas sejam ditas. Essas coisas vou dizê-las, não gritá-las. Pois há muito tempo que o grito não faz mais parte de minha vida. Faz tanto tempo... Porque escrever esta obra? Ninguém a solicitou. E muito menos aqueles a quem ela se destina. E então? Então, calmamente respondo que há imbecis demais nesse mundo (FANON, 2008, p. 25).

\section{INTRODUÇÃO}

\section{Os efeitos foucaultianos: saber, poder e subjetividade}

Passados vinte e quatro anos de sua morte e as reflexões levantadas por Michel Foucault continuam a exercer fortes influências sobre o saber em geral. Seus focos de problematização em torno dos discursos das relações de poder e das práticas de si auxiliam a re-contextualizar a concepção de História tomada não a partir dos grandes acontecimentos, nem das metanarrativas heróicas dos grandes nomes da humanidade, mas sim na multiplicidade dos agenciamentos e na exterioridade do acidente. História, portanto, sinônimo de campo de possibilidade e condição de legitimidade enunciada por estratos. Auxilia também a pensar outra proposta de Sociologia, não como leitura dos grandes sistemas de poder alocados numa concepção jurídica que confere a este substantivo um local de ação. Para além dessa perspectiva, a noção de genealogia procura traçar leituras transversais sobre o poder, marcando sua capilaridade e sua positividade, emergindo o que Foucault (1979) chamou de microfísica do poder. Por fim, uma crítica com relação a certas tradições psicológicas que entendem a subjetividade através de uma concepção anistórica e universalizada, o que é passível de problematização, na medida em que seus estudos abrem à probabilidade para se pensá-la como resultante do entrecruzamento de forças e como uma produção atravessada pelas esferas políticas das relações do sujeito com a verdade, com o discurso, com o poder e com a ética.

Então, diante de tais contextualizações, é impossível levar em conta o que propôs o sociólogo Jean Baudrillard (1984). Esquecer Foucault? Certamente que não. Mais gratificante é aprofundar o estudo em torno do seu pensamento a título de diálogo não para procurarmos por uma essência, mas sim para fazermos como ele mesmo sugeriu uma "ontologia histórica de nós mesmos".

Apontado equivocadamente por muitos de seus críticos como um teórico do poder ou ainda como crítico relativista das ciências humanas, Michel Foucault, principalmente a partir do final dos anos 1970, procura contextualizar que o panorama de seus estudos se refere a um questionamento sobre o sujeito nas suas diversas nuances. Na opinião de Marcio Goldman (1998), essa história do sujeito seria um dos maiores projetos elencado por Foucault ao longo de sua trajetória intelectual. Afinal como ele mesmo lembra "não é o poder, mas o sujeito, que constitui o tema geral de minha pesquisa" (FOUCAULT, 1995a, p. 233). 
A subjetividade seria o tema central nos seus escritos recebendo um tratamento crítico que tem como alvo os estatutos do sujeito do conhecimento, do indivíduo cerceado pelas relações de poder e o sujeito ético/moral.

Kleber Prado Filho (1998) argumenta que, para Foucault, a modernidade é a "idade do homem". Tal afirmação possibilita pensar esse momento histórico sob um ponto de vista que toma o conhecimento como uma produção que perpassa o sujeito, se dirige a ele, se refere a ele, de um modo intenso, jamais observado em outros tempos.

Logo, a subjetividade deve ser entendida como parte integrante desta grande maquinaria moderna correlativa às mais variadas práticas sociais, sejam as de ordem discursiva, sejam aquelas presentes no campo dos dispositivos, sejam as que se dão pelos processos de subjetivação.

O presente trabalho tem por finalidade percorrer alguns desses escritos foucaultianos, levantando nas suas superficialidades e porosidades os aspectos políticos e históricos da subjetividade.

Nesse sentido, a trajetória a ser percorrida pelo texto debruçar-se-á sobre a questão tomando os percursos epistemológicos e metodológicos de Michel Foucault, não enquanto uma linearidade cronológica, mas sim nos seus deslocamentos possíveis em que se constata em um primeiro momento a existência da problematização arqueológica da subjetividade, na qual Foucault oportunizará uma crítica ao estatuto do sujeito do conhecimento em detrimento ao aparecimento do sujeito do enunciado constituído por jogos de objetivação e de linguagem. O segundo deslocamento apresenta as contribuições genealógicas do indivíduo moderno imerso nas relações de poder. Por fim, o terceiro deslocamento se debruça sobre a problematização ética da subjetividade presente nos últimos trabalhos de Michel Foucault, reiterando a presença de um sujeito ético que se relaciona consigo mesmo a partir de diferentes experiências.

\section{Primeiro deslocamento:}

\section{Problematização arqueológica da subjetividade}

Com relação aos seus estudos cuja perspectiva de método é a arqueologia, existe no pensamento foucaultiano a constatação, ainda que implícita, de como na modernidade se formam certos regimes de discursividade que produzem os sujeitos através de movimentos analíticos em torno da verdade.

Revisitando textos dessa época como O nascimento da clínica, As palavras e as coisas, e A arqueologia do saber (FOUCAULT, 2008, 2007, 2004a), é possível constatar a sua crítica em relação ao sujeito cognoscente e suas categorias como: autonomia, liberdade, racionalidade, etc. Os variados temas presentes nesses livros auxiliam a colocar em suspenso esses estatutos nos quais o pensamento moderno se encontra atrelado desde Kant através da figura do sujeito transcendental. 
De acordo com Arthur Arruda Leal Ferreira (2006), o sujeito transcendental é aquele que sintetiza o atributo da razão com a possibilidade da experiência do objeto permitindo-lhe assim agir sobre ele de modo a não contaminá-lo com fatores subjetivos.

É justamente contra essa noção que a arqueologia coloca o problema da subjetividade nos jogos de enunciação. Quer dizer, não se trata de reiterar a presença de uma consciência fundadora que atribui significados para as coisas, mas sim destacar os lugares possíveis para o sujeito no atravessamento dos saberes. O que está presente nessa perspectiva é a própria sujeição às regras de produção do/pelo conhecimento.

À pretensa hegemonia do homem no domínio do saber, Foucault (2007), escreve num de seus escritos mais polêmicos, como essa figura é uma invenção recente na história. Afirma ele que o sujeito não é o mais antigo dos problemas no contexto dos sistemas de pensamento. Consequentemente, a questão passa pela própria recusa da noção de sujeito como categoria filosófica, apontando no tema da "morte do homem" as ruínas desse império.

Tomando-o como uma produção histórica, é possível observar a existência do sujeito do enunciado, objetivado e atingido pelos discursos. Esse jogo objeto X sujeito, o qual Foucault chama de objetivação, pode ser entendido como uma prática em que há o cruzamento e a troca de estatutos de identidades, no qual o sujeito ora assume as características do objeto, ora o objeto assume as características de sujeito.

Por exemplo, o livro O nascimento da clínica (FOUCAULT, 2008) traça uma arqueologia do olhar médico e dos sujeitos que são constituídos no limiar de práticas e experiências, desenhando as linhas correlativas das doenças e dos corpos que intensificam as suas relações e funções. De acordo com Arthur Arruda Leal Ferreira (2005), essa intensificação da experiência médica regulada pelas articulações entre o visível e o dizível remete à existência de uma "anatomia-clínica moderna" que direciona o seu olhar sobre a patologia, não a partir dos signos, mas sim no volume corporal dos tecidos. A clínica aparece como um movimento empírico-prático que potencializa o saber médico, saber este que corrobora o aparecimento de uma ciência do indivíduo tomado como objeto.

Como se pode observar, nesse contexto da arqueologia, o que se abre é uma ontologia histórica que possibilita o aparecimento de outro olhar em torno da questão da subjetividade, no sentido de entendê-la como um modo de relação entre os regimes de produção de verdades e o conjunto de práticas discursivas presentificadas no jogo da objetivação. 


\section{Segundo deslocamento:}

\section{Problematização genealógica da subjetividade}

Se na proposta recoberta pela arqueologia o que esta em jogo são os procedimentos de produção de saberes correlativos aos regimes de verdade no início dos anos 1970, com o acoplamento de uma analítica do poder, o eixo de estudo foucaultiano passa a ser caracterizado também pelo estudo de uma nova economia do poder moderno.

Nas múltiplas possibilidades de análise que o livro Vigiar e punir (FOUCAULT, 1987) suscita, se encontra a problematização da genealogia do indivíduo moderno em face de uma complexa malha de dispositivos que se efetivam mediante estratégias de poder. Esse projeto apresenta a emergência da noção de indivíduo situado na fronteira dessas relações. Uma genealogia que tem, portanto, a ver com uma história do presente. Quem somos nós? Este questionamento desloca o entendimento essencializado da figura do indivíduo em detrimento ao campo de estudos cujo foco diz respeito aos acontecimentos históricos e à intensa batalha entre as forças, o duelo da "Atividade" contra a "Reatividade". Paul Veyne (1987) apresenta interessante consideração acerca do indivíduo moderno. Ressalta ele que:

Entende-se aqui, por indivíduo, um sujeito, um ser ligado à sua própria identidade pela consciência ou pelo conhecimento de si. Suponhamos que esse sujeito no sentido filosófico da palavra é também um sujeito político da mesma palavra; suponhamos que é o sujeito de um rei; nesse caso não obedecerá na inconsciência, como tudo indica que fazem os animais, pensará algo da sua obediência e do seu amo, e também de si mesmo como sujeito dócil ou indócil do seu rei. No sentido que aqui atribuímos à palavra, um sujeito não animal dum rebanho; é, pelo contrário, um ser que dá valor à imagem que tem de si mesmo. A preocupação com esta imagem pode leválo a desobedecer, revoltar-se, mas pode também, e é o que sucede mais freqüentemente, levá-lo a obedecer ainda mais; entendida neste sentido, a noção de indivíduo não se opõe de modo algum à noção de Sociedade ou de Estado. Pode então dizer-se que esse indivíduo é atingido no coração pelo poder público, quando é atingido na sua imagem de si, na relação que tem consigo mesmo quando obedece ao estado ou à sociedade (VEYNE, 1987, p. 09-10).

O indivíduo é, portanto, o alvo desse esquadrinhamento histórico. Esquadrinhamento se refere ao conjunto de práticas políticas e sociais: são as disciplinas, os exames, as vigilâncias, por exemplo. Todas elas responsáveis por instaurar uma fina película reguladora das estratégias de poder. 
É importante lembrar que essa genealogia do indivíduo nada tem a ver com uma tentativa, por parte de Foucault, de construir uma história das técnicas e das formas de dominação. O que está em jogo nessa proposta é a possibilidade de se contornar as diferenças, e os enfrentamentos no interminável jogo das proveniências e das emergências. Então, pode-se dizer que o interesse de Michel Foucault não é o de tomar o homem como objeto de exploração ao longo da história. A inscrição da genealogia passa pela delimitação de como na sociedade moderna os corpos são produzidos, mostrando quais os enredos e sua utilidade no contexto do capitalismo ocidental.

Se Vigiar e punir oferece uma análise genealógica do indivíduo moderno, em $A$ vontade de saber (FOUCAULT, 1977), vê-se apresentar a problemática da subjetividade acoplada no desenvolvimento de um poder sobre a vida. O biopoder inaugurado na modernidade cuja eficácia diz respeito ao desenvolvimento de novas estratégias cuja dimensão passa pela regulação dos corpos, dos estudos demográficos e da estatística populacional sob o pretexto de protegê-la. Foucault (1977) aponta que esse biopoder se efetiva mediante dois pólos de desenvolvimento, sendo eles: o aparecimento das disciplinas do corpo e a fusão de práticas de regulação da população.

As disciplinas do corpo e as regulações da população constituem os dois pólos em torno dos quais se desenvolveu a organização do poder sobre a vida. A instalação durante a época clássica, desta grande tecnologia de duas faces anatômica e biológica, individualizante e, especificamente, voltada para os desempenhos do corpo e encarando os processos da vida - caracteriza um poder cuja função mais elevada já não é mais matar, mas investir sobre a vida de cima a baixo (FOUCAULT, 1977, p. 131).

Dessa junção na qual a face anatômica e a biológica estão inscritas é que derivam aspectos que agem sobre a intimidade. Tem-se, nesse caso, a normalização como via de regra aos fatores que envolvem os cuidados e as políticas de higienização, de alimentação, e o controle das taxas de natalidade e de mortalidade. Aqui a subjetividade aparece como uma produção regulada na caracterização de parâmetros que intensificam a vida.

Outro ponto relevante em A vontade de saber (FOUCAULT, 1977) corresponde ao estudo em torno da formação das práticas confessionais do Ocidente, correlativo ao conjunto de discursividades que interpelam o sujeito a enunciar a verdade sobre si. De proveniência cristã, a confissão passa a se estender principalmente a partir do século XVIII por todo o corpo social, sendo incorporada por inúmeros campos de saber. Está presente na forma de interrogatórios, narrativas, documentos, análises etc. Confissão como tecnologia, em que é possível desvelar todos os segredos. De acordo com Kleber Prado Filho (2006), ela é uma tecnologia, pois articula um conjunto embricado de saberes que se desdobram em meio a questões relativas à subjetividade. A confissão é o momento de o sujeito 
exercitar um discurso com relação a si mesmo, oportunizando uma revelação da verdade. Em outras palavras, essa tecnologia confessional enuncia o que o sujeito é por meio do conhecimento de si.

\section{Terceiro Deslocamento:}

\section{Problematização ética da subjetividade}

Se os anos 1960 e 1970 são marcados pela crítica foucaultiana à figura do sujeito do conhecimento e também às relações de poder que produzem indivíduos por meio de apertados jogos de identidade, os seus últimos escritos apresentam um novo deslocamento metodológico cuja dimensão se efetiva dentro de um projeto conhecido por "Genealogia da Ética da Sociedade Ocidental" (FOUCAULT, 1995b, p. 262). Qual a inovação dessa genealogia da ética? Pela primeira vez o ponto de interrogação não é lançado em direção ao aparecimento da modernidade pelo "Historiador do Presente", pois os livros O uso dos prazeres (FOUCAULT, 1984), e O cuidado de si (FOUCAULT, 1985), assim como os seus últimos cursos no Collège de France, têm como foco os períodos da cultura greco-romana e o nascimento do cristianismo. Outro ponto que merece destaque é o desdobramento da noção de subjetividade, tida até então como um processo de sujeição, para a compreensão em torno da questão enquanto prática de assujeitamento referente ao movimento que se forma nas relações do sujeito consigo mesmo em distintos tempos históricos e segundo certos critérios éticos e morais.

Não obstante, Foucault não faz uma história da filosofia. Não lhe interessa em momento algum relatar qual a concepção de homem dos pensadores antigos. Também não é sua intenção construir um tratado sobre ética no sentido de uma "teoria filosófica da moral" tendo como ponto de partida o estudo dos códigos e legislações existentes. Sua intenção é mais simples: trata-se de recorrer à vasta literatura existente para contextualizar, nos discursos prescritivos de textos clássicos, os elementos da doutrina amplamente difundida no mundo antigo, e que será relegada ao segundo plano pela filosofia moderna: trata-se da noção de epimeléia heautô, ou seja, o preceito de que em primeiro lugar, é preciso cuidar de si mesmo.

Para Foucault (2004b), o cuidado de si corresponde a uma atitude filosófica que perpassa todos os limites da cultura greco-romana e que encontra em Sócrates o seu maior mestre. Ele é o primeiro a assumir para si a responsabilidade em interpelar os sujeitos a cuidarem de si mesmos. Assim o faz quando enfrenta os seus acusadores como registra o texto Apologia de Sócrates (PLATÃO, 2004) apresentando os três preceitos que fazem dele um homem de virtude. Em primeiro lugar, porque cumpre uma missão dada pelos próprios deuses, missão esta que levará a cabo até o último de seus dias. Em segundo lugar, se trata de uma tarefa desinteressada da qual não espera nenhuma retribuição. Finalmente, se trata de uma função útil para a polis, tão necessária quanto a conquista de um novo território, pois ensinar para um jovem os preceitos da epimeléia heautoû é presentear Atenas com um cidadão apto a exercer o governo de modo democrático e livre da tirania. 
Nesse sentido, o cuidado de si equivale ao direcionamento da conduta por parte do sujeito. Tal constatação vislumbra, também, o próprio redimensionamento histórico da tradição filosófica respaldada pelo preceito do conhece-te a ti mesmo (gnôthi seautón). Na realidade, o conhece-te a ti mesmo nada tem a ver com um modelo ideal de vida, mas corresponde unicamente à inscrição que é da ordem da vigilância. Foucault (2004b) lembra que tal regra não se refere, dentro da cultura grega ao conhecimento de si, mas marca uma recomendação a todos aqueles que procuram pelos deuses. Antes de se colocar qualquer questão é imprescindível um exame minucioso a fim de que se pergunte somente o necessário. O gnôthi seautón inscrito na porta do oráculo tem por objetivo estabelecer o imperativo de prudência aos que procuram interpelar os deuses tal qual os outros dois preceitos: o medèn ágan (nada em demasia), princípio no qual o sujeito jamais deve perguntar demasiadamente, e o engýe (cauções) recomendação de que o indivíduo jamais faça promessas que não possa cumprir. Portanto, o conhece-te a ti mesmo não se refere à tentativa por parte dos gregos, em fundar as bases da "interioridade", e, nesse sentido, a proposta foucaultiana consiste em inserir a desconstrução dessa concepção em nome da problematização em torno da experiência ética do cuidado de si.

A questão elencada por Foucault sobre a existência de um sujeito ético entra em conflito com outras teorias que concebem o indivíduo a partir de funções puramente metafísicas. Uma história da subjetividade, nos dizeres de Frederic Gros (2006), se refere ao movimento político que debate a produção de subjetividade nos seus múltiplos atravessamentos e distintas experiências éticas que fazem do sujeito mais um mosaico do que propriamente o resultado de um projeto evolucionista cujo ápice é à modernidade.

O curso proferido por Foucault na passagem de 1980 para 1981, intitulado Subjetividade e verdade tem como proposta anunciar a possibilidade dessa história política da subjetividade correlativa à trajetória ética do cuidado de si. Reproduz-se abaixo um trecho no qual tal proposta é levantada:

A história do cuidado e das técnicas de si seria, portanto, uma maneira de fazer a história da subjetividade; porém, não mais através da separação entre loucos e não loucos, doentes e não doentes, delinqüentes e não delinqüentes, não mais através da constituição de objetividade científica, dando lugar ao sujeito que vive, que fala e que trabalha. Mas através do empreendimento e das transformações, na nossa cultura, das "relações consigo mesmo", com seu arcabouço técnico e seus efeitos de saber (FOUCAULT, 1997, p. 111).

Pensar o cuidado de si como possibilidade de compreensão dos processos de subjetivação equivale a problematizar a própria psicologia uma vez que algumas correntes desse campo concebem a subjetividade tendo como pressupostos conceitos como singularidade, interioridade, normalidade, identidade, e personalidade, por exemplo. Na contramão dos psicologismos, o pensamento de Foucault, proveniente das práticas de si, oportuniza o debate em torno dos jogos 
de identidade em detrimento à analítica das experiências éticas em de diferentes processos de estética da existência, de cuidado com o corpo e com a alma, e ainda da decifração dos sentidos e dos exames de consciência.

De certa maneira, Foucault nos convida não a descobrir o que somos, mas sim a recusar aquilo que nos tornamos. Ou seja, a questão não passa pelo desvelamento nem pelo retorno à nossa matriz identitária, mas sim pela intensa relação política dos modos pelas quais a subjetividade é produzida nos seus mais variados dispositivos e agenciamentos. O que somos nós? Uma pergunta inútil do ponto de vista foucaultiano, melhor é lançar os seguintes questionamentos: o que estamos fazendo de nossas vidas? Quais os processos de subjetivação que devemos recusar e resistir na contemporaneidade? Existir é resistir, significa também se trabalhar e experienciar a vida não a tomando como ponto de contemplação, mas sim como resultante de um intenso processo tangenciado pelo saber que nos produz, pelo poder que nos disciplina e controla e pela ética que faz com que o sujeito possa se relacionar consigo mesmo segundo certos critérios.

\section{CONSIDERAÇÕES FINAIS}

A leitura acerca da história política da subjetividade em Michel Foucault coloca em evidência as suas formas de produção nas relações concretas e não em universalismos. Trata-se também de deslocar tal conceito do plano das metanarrativas e inserí-lo no terreno arenoso da política e da história.

Com relação ao regime discursivo, constata-se uma crítica ao sujeito cognoscente em detrimento ao sujeito do enunciado. Sujeito do enunciado que por sua vez é preponderantemente constituído pela linguagem, e que, portanto, se encontra em uma situação de sujeição ante a objetivação do discurso. O discurso deve ser entendido como sinônimo de atividade política que interpela e produz os sujeitos segundo certos critérios. Nesse eixo subjetividade X discurso, evidenciase o enfrentamento com relação à autonomia do indivíduo face aos objetos e na sua suposta capacidade em atribuir-lhes significados.

No que diz respeito ao eixo subjetividade $\mathrm{X}$ relações de poder, o foco recai sobre os modos de sujeição presentes na sociedade moderna na qual se pode encontrar o projeto de uma genealogia do indivíduo intimamente relacionado com os jogos de identidade, assim como às técnicas de disciplina e de controle sobre a vida.

Num outro patamar, observa-se a leitura sobre a subjetividade nas relações do sujeito consigo mesmo passando de uma hermenêutica de si para o estudo em torno das práticas de si e dos modos de experiência ética. Opera nesse segmento a possibilidade de compreensão do processo de subjetivação não mais sobre a égide de uma matriz epistemológica demasiadamente culturalista, que entende que sejamos o resultado de um longo processo cultural-evolutivo que remonta à Grécia Antiga e atinge seu clímax na Modernidade, nem tampouco uma compreensão biologicista da subjetividade. 
Também se deve dizer que a história da subjetividade não corresponde à tentativa de articulação de uma teoria do sujeito, nem se aproxima de qualquer compreensão psicológica justamente porque o seu tratamento crítico diz respeito à construção de uma analítica que é assistemática, fragmentária e descontínua. Quer dizer, sua fundamentação não ocorre sob certos preceitos e critérios de regularidade e de linearidade. Muito menos não procura fundar conceitos no estabelecimento de certas regras de validação e de cientificidade no sentido hard da palavra. Antes, arriscaríamos dizer, ela é permeada pelas condições de possibilidade das práticas que agem na ordem discursiva, em matrizes capilares de relações de poder, e, por fim, em processos de subjetivação. Ela deriva, portanto, do entrecruzamento de todas essas tecnologias.

Quanto aos seus relevos, uma história da subjetividade não deve ser confundida como uma visão pessimista de mundo. Contra toda espécie de fatalismo é que se vislumbram, nesses eixos, elementos para se pensar as linhas de fuga que seriam táticas de guerrilha, tal qual sugere Gilles Deleuze (2000), e que agem no terreno da regionalização e da transversalidade.

Sendo assim, na arqueologia encontra-se a figura da transgressão que opera seu agenciamento a partir do escape às regras e aos efeitos de enunciação dos discursos. O papel político da transgressão implica na transposição a esses regimes que se colocam como hegemônicos e verdadeiros.

Quanto à problematização genealógica, encontra-se como linha de fuga as práticas de resistência referentes a modos criados pelos indivíduos de resistir à intensa e complexa malha de poder que os atravessa. Constatando que o sujeito está mergulhado nos jogos de poder, a resistência inaugura a possibilidade de enfrentamento enquanto atitude-limite frente as relações de poder.

Por fim, quanto ao contexto da ética, há que se ressaltar a possibilidade da criação, por parte do sujeito, daquilo que Foucault (2004c) chama de práticas de liberdade. No entanto, liberdade aparece aqui não com a conotação abstrata que lhe atribui a tradição contratualista, por exemplo. Liberdade como prática, pensada por Michel Foucault corresponde, antes de tudo, à possibilidade de criação por parte do sujeito e de enfrentamento aos modos de sujeição pelos quais se é interpelado.

Portanto, as práticas de liberdade, bem como as estratégias de resistência e a transgressão aos discursos se efetivam enquanto possibilidades concretas de problematização ante os modos de subjetivação contemporâneos, compreendendo sua produção a partir de um ponto de vista histórico e político. 


\section{REFERÊNCIAS}

BAUDRILLARD, J. Esquecer Foucault. Rio de Janeiro: Rocco, 1984.

DELEUZE, G. Conversações. Rio de Janeiro: Ed. 34, 2000.

FANON, F. Pele negra, máscaras brancas. Salvador: Bahia: EDUFBA, 2008.

FERREIRA, A. A. L. O múltiplo surgimento da Psicologia. In: FERREIRA, A. A. L.; JACÓ-VILELLA, A. M. (Org.). História da Psicologia: rumos e percursos. 1. ed. Rio de janeiro: NAU, 2006. p. 13-46.

. A Psicanálise e a Psicologia nos Ditos e Escritos de Michel Foucault. In: GUARESCHI, N.; HÜNNING, S. (Org.) Michel Foucault e a História da Psicologia. Porto Alegre: Abrapso Sul, 2005, v. 1, p. 29-72.

FOUCAULT, M. História da sexualidade I: a vontade de saber. Rio de Janeiro: Graal, 1977.

. Microfisica do poder. Rio de Janeiro: Graal, 1979.

1984.

. História da sexualidade II: o uso dos prazeres. Rio de Janeiro: Graal, 1985.

. História da sexualidade III: o cuidado de si. Rio de Janeiro: Graal,

. Vigiar e punir: nascimento da prisão. Rio de Janeiro: Vozes, 1987.

. O sujeito e o poder. In: DREYFUS, H.; RABINOW, P. (Org.). Michel Foucault: uma trajetória filosófica para além do estruturalismo e da hermenêutica. Rio de janeiro: Forense Universitária, 1995a. p. 231-249.

Sobre a genealogia da ética: uma revisão de trabalho. In: DREYFUS, H.; RABINOW, P. (Org.). Michel Foucault: uma trajetória filosófica para além do estruturalismo e da hermenêutica. Rio de janeiro: Forense Universitária, 1995b. p. 253-278.

J. Zahar, 1997.

Resumo dos Cursos do Collège de France (1970-1982). Rio de Janeiro: . A arqueologia do saber. Rio de Janeiro: Forense Universitária, 2004a. . A hermenêutica do sujeito. São Paulo: Martins Fontes, 2004b. 
FOUCAULT, M. A ética do cuidado de si como prática de liberdade. In: MOTTA, M. B. (Ed.) Ética, sexualidade, politica. Rio de Janeiro: Forense Universitária, 2004c. p. 264-287. Coleção Ditos e Escritos, vol.V.

. As palavras e as coisas: uma arqueologia das ciências humanas. São

Paulo: Martins Fontes, 2007. . O nascimento da Clínica. Rio de Janeiro: Forense Universitária, 2008.

GOLDMAN, M. Objetivação e subjetivação no "Último Foucault". In: BRANCO, G. C.; NEVES, L. F. B. (Org.). Michel Foucault: da arqueologia do saber à estética da existência. Rio de Janeiro: NAU, 1998. p. 85-104.

GROS, F. O cuidado de si em Michel Foucault. In: RAGO, M.; VEIGA-NETO, A. (Org.). Figuras de Foucault. Belo Horizonte: Autêntica, 2006. p. 127-138.

PLATÃO. Apologia de Sócrates. São Paulo: Nova Cultural, 2004. Coleção Os Pensadores.

PRADO FILHO, K. Trajetórias para a leitura de uma história crítica da subjetividade em Michel Foucault. 1998. Tese (Doutorado)-Universidade de São Paulo, São Paulo, 1998.

. Uma genealogia das práticas de confissão no ocidente. In: RAGO, L. M.; VEIGA-NETO, A. (Org.) Figuras de Foucault. Belo Horizonte: Autêntica, 2006. p. 139-148.

VEYNE, P. O indivíduo atingido no coração pelo Poder Público. In: VEYNE, P. et al. (Org.). Indivíduo e poder. Lisboa: Edições 70, 1987. p. 9-23.

Recebido em: agosto de 2008

Aceito em: dezembro de 2008 